\title{
About the high capacity public transport networks territory functions
}

\author{
Ş. Raicu, V. Dragu, M. Popa \& Ş. Burciu \\ Department of Transport, Traffic and Logistics, \\ University "Politehnica" of Bucharest, Romania
}

\begin{abstract}
A transit system's infrastructure (tramways, underground or light rails) plays a major role in satisfying people's need for mobility - by size and the stability of their operation, and also by the independence of their quality performance compared to cars facing traffic congestion, because of their dedicated operation. We analyzed the potential transport capacity of the transit network infrastructures in order to define their territory functions, through urban people and poles to determine daily urban mobility preferences (for work, study, business purposes) and occasional mobility (for sports, tourism, culture, health caring purposes). In a structured space (Bucharest city), using a GIS map and TranCAD software, we defined the cover/serve index for the 72 study areas. (quasi-homogenous areas regarding their social-economic activities). We determined a hierarchy of those areas which help to establish directions to adapt transit infrastructure topology to the fast growing rate of the urban development. The territory functions characterization of the transit networks is used also to determine the hierarchy of the most highly attractive centroids (using an index that takes also into account both people density of the different areas and the distance to the popular centroids). The results of the study emphasize the disparities in urban territory served by the transit transport infrastructure; they can represent a useful tool in transit networks development strategies.
\end{abstract}

Keywords: transit networks, network topology, urban mobility, territory functions, accessibility, attractiveness.

\section{Introduction}

Urban transport systems with high capacity (tramway, underground or light railways), usually named as transit systems, play a major role in satisfying 
people's mobility - by size and the flow's stability and also by their quality performances (because of their dedicated or exclusive service).

Examining the urban area as a territory system - consequences of human activities, allow us to emphasize the role of a transport infrastructures for defining the territory relational functions, social-economical links among activities $[8,12]$. These territory functions, having local or regional importance, are the consequences of the connection between the networks' properties (convexity, connectivity, homogeneity, isotropy, nodality) and the socioeconomic activities on a certain space, which became a cohesion territory with satisfied people's mobility.

In a synthetic evaluation, the role of the urban transport infrastructures in satisfying people's mobility is revealed by accessibility. A well known definition of spatial accessibility is the way of goods or people getting from one place to another with some or all transport modes. The several transport modes are connected according to the certain chosen criteria, according to the individual's interest or to the transport system operation.

Accessibility, in the simplest approach, as the length of the route from origin to destination, is an exclusive characteristic of a route's topology and geometry and so, is a feature of network infrastructure [3]. According to the other approach (including travel time, cost, comfort, safety measurements) the accessibility depends both on the network topology and on a transport means characteristics (for individual car) and on the operating technologies used (routes, transport means, schedule - for public transportation).

There is no universally acknowledged definition of accessibility. Different theoretical backgrounds and space complexity have been involved and implemented in empirical investigation. A location is assumed to be accessible if it is connected to other locations via a link to a transport network [2]. Various researchers have related accessibility between supply and demand of goods and services to economic growth $[2,7]$. There are important studies on the accessibility indicators as perceived measures that represent the behaviour issue [10]. There are also indicators based on spatial opportunity well known as gravity approach $[5,6]$, the most used model, with early development made by Hansen [4]. Quite popular accessibility indicators are based on a timeconstrained approach. The space-time prism projected on two-dimensional space represents the potential path area covered by the individual with a given time budget [9].

Some of the accessibility measures were compared in a valuable empirical paper [1] for about 4500 major European cities to reveal their performances and also to examine the effects of the functional forms of deterrence variable and agglomeration effects.

Putting aside the measurement of spatial accessibility offered by the transport network we can conclude that accessibility is an expression of the mobility supply (as an ex-ante approach) for the social-economical activities within a certain space, which is itself a consequence of the land-use actions. Considering accessibility as a transport system characteristic (in which infrastructure plays an essential role) its measure has to reflect the social utility, as the mobility 


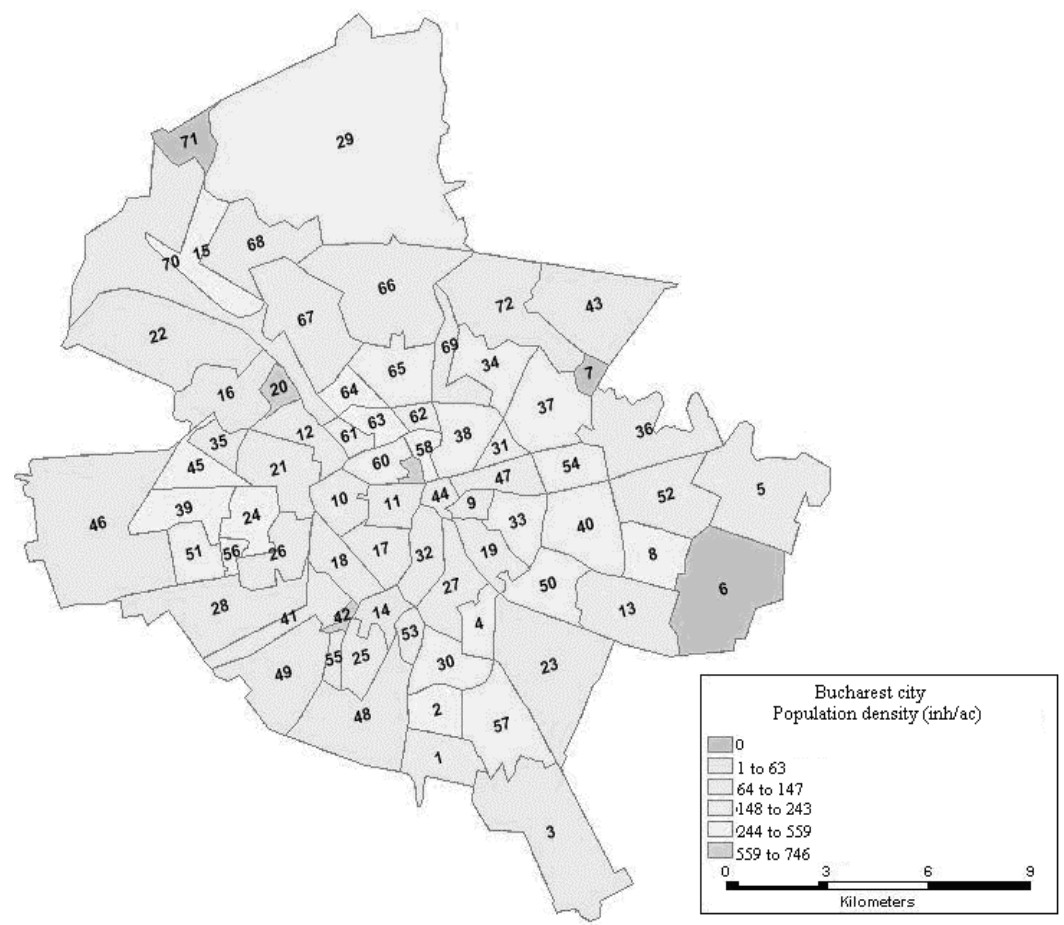

Figure 1: Homogenous areas of Bucharest city (according to GUP).
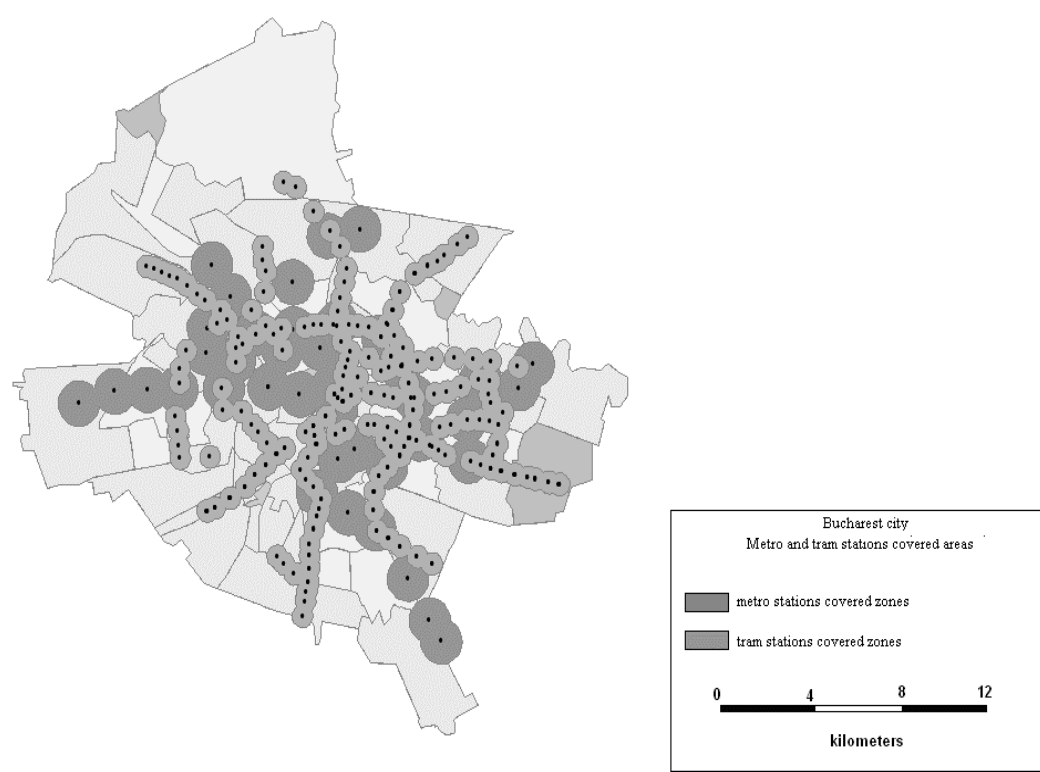

Figure 2: High capacity infrastructure network covered zones. 
potential provided by the transport system (ex-ante approach) as well as the satisfied social mobility (ex-post approach).

As social mobility is dependent on people's distribution within an urban territory, the present paper emphasizes the link between Bucharest transit transport infrastructures and the resident population in different homogenous areas of the urban territory. After that, we will extend the accessibility evaluations, in relation to major interest sites (work places, study, recreational and commercial places), taking into consideration the technological characteristics of transit services provided by the major public operators in Bucharest (METROREX and RATB).

Both in regard to the infrastructure and operating technologies, spatial differences of territory functions assured by the urban transit networks were emphasized, with value in further land use and transport planning.

\section{Infrastructure network - urban territory correlation}

The cover/serve index of urban territory by high capacity public urban transport networks was evaluated (for tram and underground). For the area covered/served by high capacity infrastructure network $(286 \mathrm{~km}$ tram railways, $66.9 \mathrm{~km}$ underground railways) in relation to the stations positions, we have considered the served areas of the ones corresponding to a circular area of $400 \mathrm{~m}$ radius around tram stations and $800 \mathrm{~m}$ for the underground ones [11]. Overlaying the map of high capacity infrastructures served areas on the one of the urban territory divided into 72 homogenous areas (according to General Urban Plan GUP) we have identified the cover index of each area (as a ratio, in percent, between the areas covered by high capacity public transport infrastructure and each area of GUP). With the help of TRANSCAD software the areas of the 72 zones of GUP and of the covered zones were determined, fig. 1 and fig. 2, and also the 72 cover levels of each zone, fig. 3. These, with values from 0 to $87.75 \%$, were grouped in 6 cover levels $(\mathrm{A}-90 \ldots 100 \%, \mathrm{~B}-80 \ldots 89.9 \%$, $\mathrm{C}-70 \ldots 79.9 \%, \mathrm{D}-60 \ldots 69.9 \%, \mathrm{E}-50 \ldots 59.9 \%, \mathrm{~F}<50 \%)$ as shown in figure 4 (cover level $\mathrm{F}$ was also divided in 5 groups, from $\mathrm{F} 1$ to $\mathrm{F} 5$ ) [13].

One can notice a weak cover (less than $35 \%$ of the 72 areas covered with high capacity public transport infrastructures have a cover index above $50 \%$ ). This conclusion does not make any difference in the areas linked to population density.

\section{Infrastructure network - urban population distribution correlation}

As the 72 homogenous of GUP have population densities among 3000 and 60000 inhabitants $/ \mathrm{km}^{2}$ we carried on characterizing high capacity public transport infrastructure by identifying the accessibility of each zone in relation with some poles of attraction (13 - educational, commercial, sportive, recreational sights) of the city. 


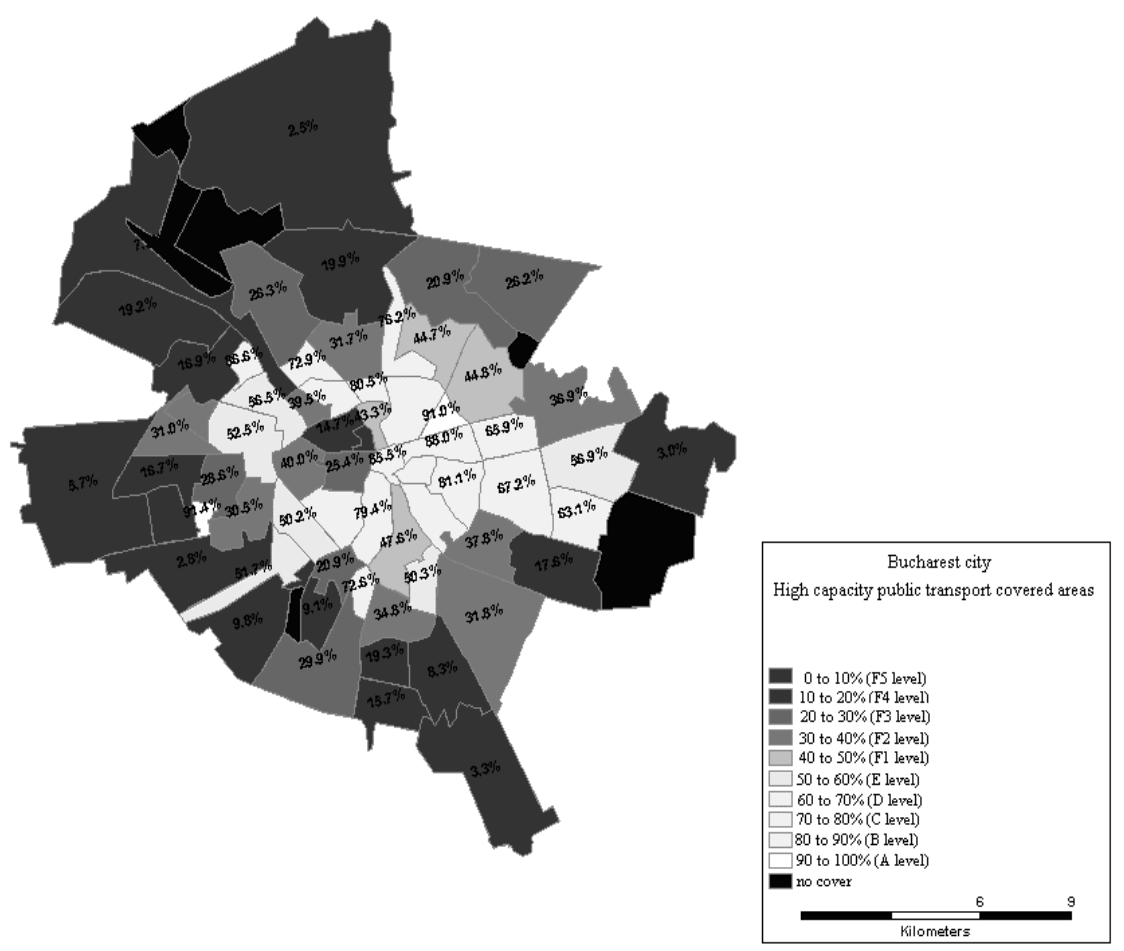

Figure 3: High capacity public transport covered area percent.

Zones number

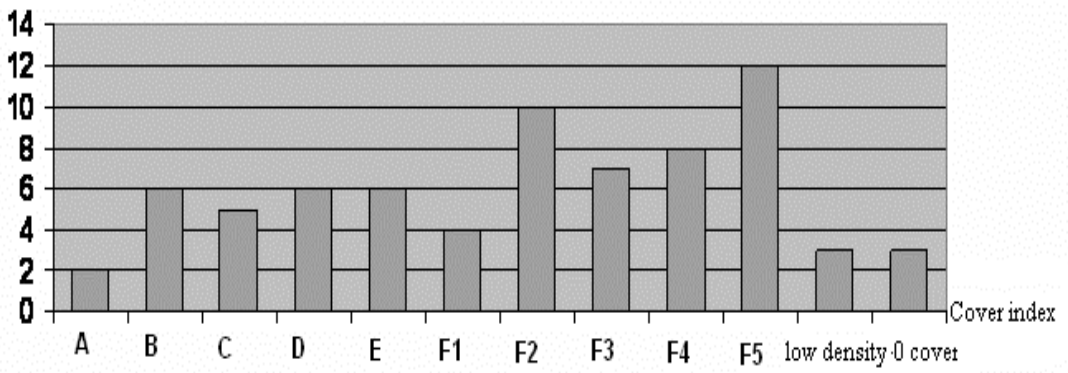

Figure 4: $\quad$ Cover indexes for the 72 areas. 


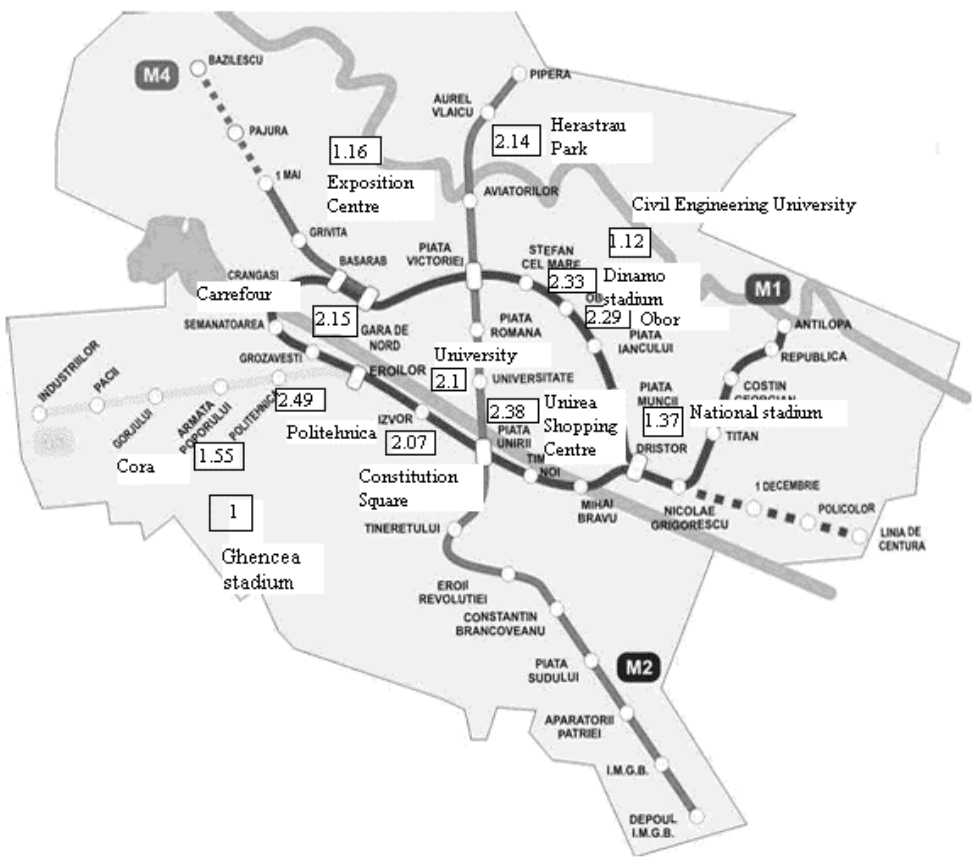

Figure 5: Underground network and relative accessibility of the 13 poles of attraction considered (reference input - Ghencea Stadium accessibility).

The accessibility of each $z$ zone in relation to each pole of attraction $i, A_{z, i}$, was considered in direct ratio to population density, $\rho_{z}$, from the $\mathrm{z}$ zone served by metro stationand in inverse ratio to movement impedance, the distance $d_{z, i}$ (from zone $\mathrm{z}$ station to the one of the pole of attraction $\mathrm{i}$, determined for the existing underground infrastructure of Bucharest):

$$
A_{z, i} \sim \rho_{z} \cdot \frac{1}{d_{z, i}} \text {, for each } \mathrm{i}=\overline{1,13} \text { şi } \mathrm{z}=\overline{1,72}
$$

or, for the accessibility of one pole of attraction, i:

$$
A_{i} \sim \sum_{z=1}^{72} \rho_{z} \cdot \frac{1}{d_{z, i}}, \text { for } i=\overline{1,13}
$$


This case also shows that high capacity infrastructure network has territory functions that emphasizes the need for better correlation between urban areas planning and the high capacity public transport infrastructure, fig. 5 .

\section{Public transport offer on high capacity infrastructure network - urban areas correlation}

The characterization of high capacity public urban transport infrastructures made so far did not take into consideration the technologies applied on these infrastructures. In regard to territory or population, infrastructures were examined as key elements of potential urban public transport offer for the city inhabitants.

Intending to characterize the present transport offer, as the four requirements of a public service are presented as population offers [12], we extended the analysis including operation technologies of the existing high capacity infrastructures (routes, traffic entities capacities and frequency).

The correlation between surface and underground high capacity public urban transport offer (tramways operated by RATB, and metro lines by METROREX), and the urban territory was achieved not in relation to the homogenous areas of GUP but with the 6 administrative sectors of the city. For each of the 40 metro stations (poles) and for the 25 representative tram stations (nodes of the network or terminals) split on the 6 sectors of the city we could determine:

NA - number of links that leave a pole;

$\mathrm{NL}$ - number of lines crossing the pole;

PDA - number of the other poles that are with direct access;

POI - number of poles reached with only one interchange;

CAP - transport capacity (maximum number of seats) of all the traffic entities passing through the pole in one hour;

FRQ - frequency, number of entities passing through the pole, on all routes, in one hour;

PA - number of accessible poles, from every pole, in a strict period (30 minutes).

For each CAP and FRQ we had different values for different periods of the day and we have characterized the metro and tram poles with the above mentioned criteria in two hypotheses:

a) all the six criteria have the same share [13];

b) different shares on criteria (NA, NL, FRQ, PA - 0.15 and PDA, 0.3 and POI, 0.1 for the metro network; NA, NL, FRQ - 0.2 and PDA, 0.3 and POI, 0.1 for the tram network).

With the help of ELECTRE method, SEMA, aggregated indicators (accessibility assimilated) were calculated for each pole both in a) and b) hypotheses. The results are presented in figure 6 and figure 7.

In regard to the considered territory, the 6 administrative sectors, fig. 8, and each high capacity public urban transport offer, major differences in serving the population can be observed, but in a global approach the complementarities of the metro and tram network leads to a more equilibrate offer, but still unequal. 


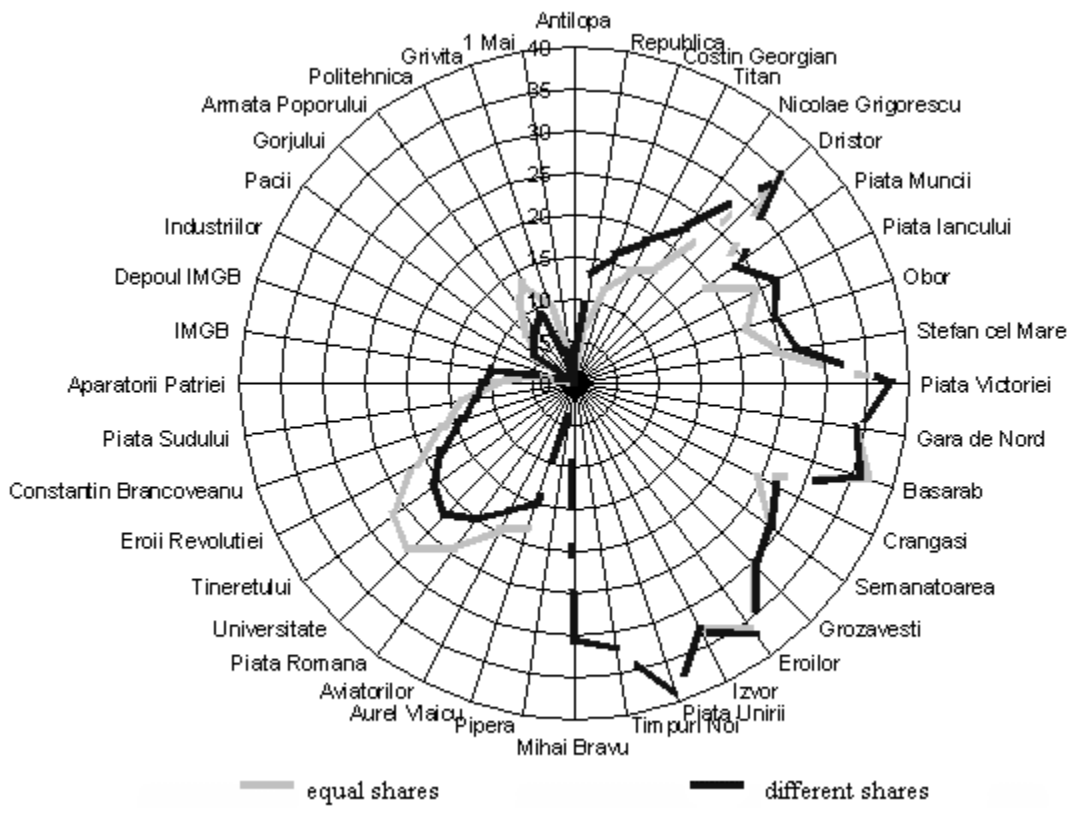

Figure 6: Metro network poles differences.

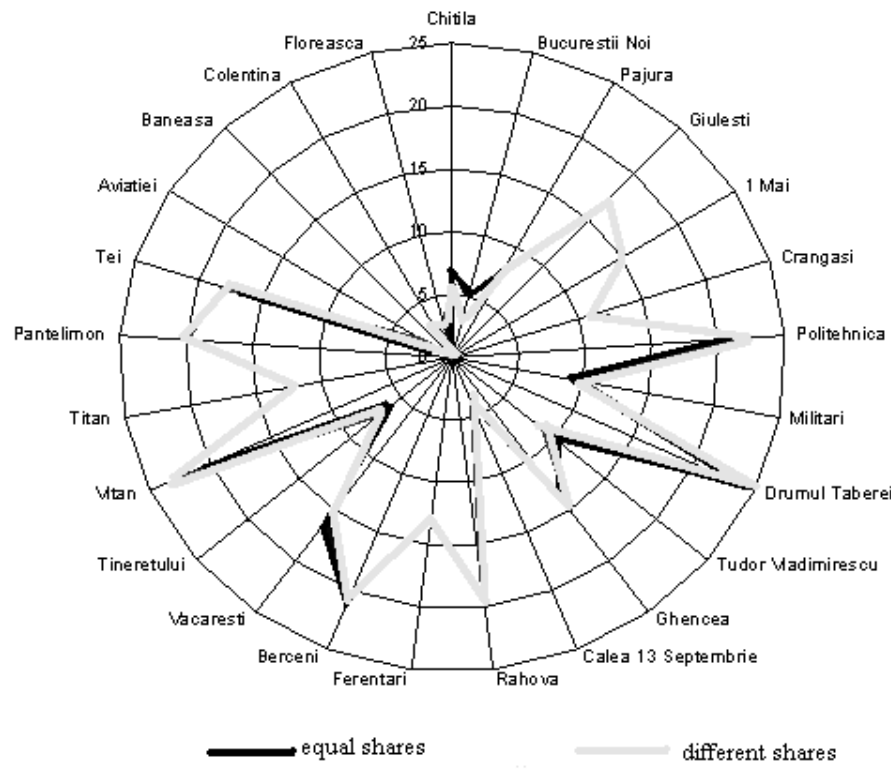

Figure 7: Tram network poles differences. 


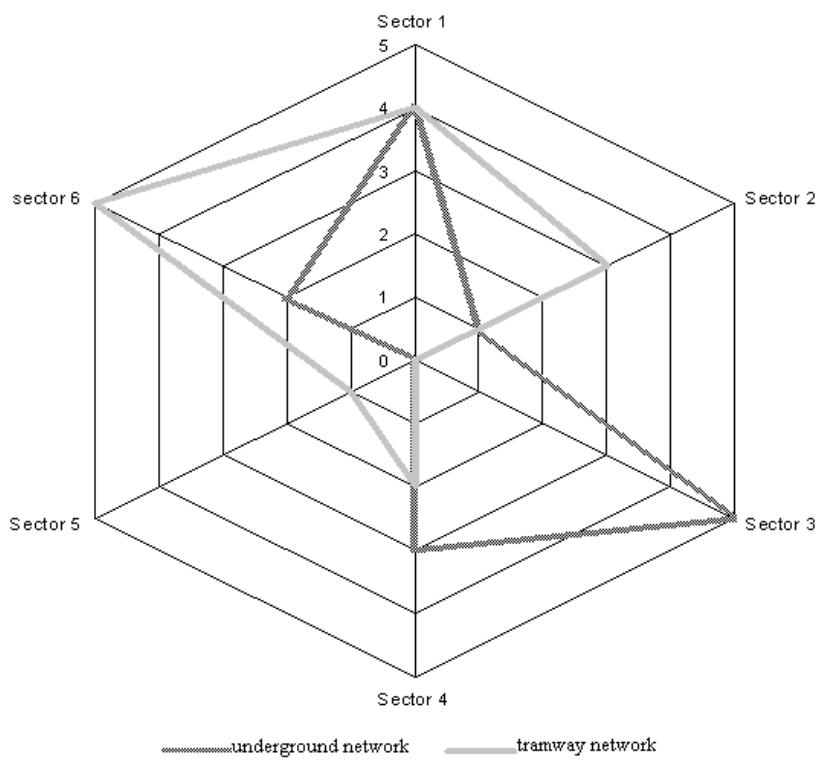

Figure 8: Spatial cover with high capacity public transport.

\section{Conclusions}

For the actual case of a large city, it was proven that the correlations between high capacity public urban transport and the urban area can be quantitative characterized.

Focused both on the accessibility given by the infrastructure and on the one assured by the global offer of the public transport system (including operating technologies of different operators), the research can be further developed with attractiveness evaluations (as an expression of the specificity of the potential need for population mobility in a certain urban area) in relation to a certain development stage of high capacity public urban transport.

The results, by the discrepancies emphasized in covering the territory with high capacity public transport offer, are appropriate to developing infrastructures and/or transport technologies and also for land use planners that aim spatial development with consequences in modifying the need for social mobility within the urban territory.

\section{References}

[1] Baradaran, S., Ramjerdi, F., Performance of Accessibility Measures in Europe, Journal of Transportation and Statistics, Sept./Dec., pp.31-48, 2001. 
[2] Bruisma, F.R., Rietveld, P., The Accessibility of the European Cities: Theoretical Framework and Comparison of Approach. Environment and Planning A. 30, pp. 499-521, 1999.

[3] Chapelan, L., Conception de services regionaux de transport public et optimation de l'offre, Raport final PREDIT, Paris, Ministere de l' Equipement, 2005.

[4] Hansen, W.G., How accessibility Shapes Land-Use. Journal of American Institute of Planners, 25, pp. 73-76, 1959.

[5] Kwan, M.P., Space-Time and Integral measures of Individual Accessibility: A Comparative Analysis Using a Point-based Framework. Geographical Analysis, 30, pp. 191-216, 1998.

[6] Levinson, D.M., Accesibility and the Journey to Work. Journal of Transport Geography, (6)1, pp. 11-21. 1998.

[7] Lundqvist, L., Planning for Freedom of Action: Spatial Interaction Theory and Planning Models. (eds.) Karlvist, Lundqvist, Snickars and Weibull, Amsterdam, 1978.

[8] Merlin, P., La planification des transports urbains: enjeux et methodes, Paris, Masson, 1984.

[9] Miller, H.J., Modelling Accessibility Using space-time Prism concepts within GIS, International Journal of Geographical Systems, 5, pp. 287301, 1991.

[10] Morris, J.M., Dumble, P.L., Wigan, M.R., Accessibility indicators for transport planning, Transportation Research part A, 13, pp. 91-109, 1978.

[11] Raicu, S. et col. Solutions for the attractivity increasing of the urban public transportation. Case study: Bucharest city and its metropolitan area. (in Romanian: Soluții pentru creşterea atractivității transportului public urban. Studiu de caz pentru Bucureşti şi aria metropolitană) research project, UPB, 2006.

[12] Raicu, Ş., Sisteme de transport, Ed. AGIR, Bucureşti, 2007.

[13] ***Transit Capacity and Quality of Service Manual - second ed. - TRB, 2003. 